\title{
EAl Endorsed Transactions

\section{Towards Smart and Sustainable Future Cities Based on Internet of Things for Developing Countries: What Approach for Africa?}

\author{
Pape Abdoulaye BARRO ${ }^{1, *}$, Jules DEGILA ${ }^{1}$, Marco ZENNARO $^{2}$, Samuel Fosso WAMBA ${ }^{3}$ \\ ${ }^{1}$ Institute of Mathematics and Physical Sciences(IMSP), Africa Center of Excellence in Mathematical Sciences and \\ Applications, Porto-Novo, Benin \\ ${ }^{2} \mathrm{~T} / \mathrm{ICT} 4 \mathrm{D} \mathrm{LAB}$, International Centre for Theoretical Physics (ICTP), Trieste, Italy \\ ${ }^{3}$ Toulouse Business School, Toulouse, France
}

\section{Abstract}

This article aims first at reviewing and discussing previous works on Internet of Things based sustainable smart cities. Secondly, it proposes an ideological and technical framework that better suits communities in future cities. At the same time, we provide a reference model that can generally apply to developing countries and specifically to Africa. This work represents a first step towards future cities and should at the same time constitute a reference base for researchers working on the same topic. Some Indexes have been leveraged to carry out this work.

Received on 30 November 2017; accepted on 08 January 2018; published on 23 January 2018

Keywords: sustainability, smart cities, future cities, embedded systems, Internet of Things, Big Data, Cloud computing and artificial intelligence.

Copyright (c) 2018 Pape Abdoulaye Barro et al., licensed to EAI. This is an open access article distributed under the terms of the Creative Commons Attribution license (http://creativecommons.org/licenses/by/3.0/), which permits unlimited use, distribution and reproduction in any medium so long as the original work is properly cited.

doi:10.4108/eai.11-9-2018.155481

\section{Introduction}

Nowadays, we are witnessing a lot of traction for the "smart city" paradigm all over the world. Various "smart cities" definitions [1], [2],[3], [7], [10], and [12] have been adopted throughout the literature. The "smart city" is primarily a concept with no clear, definitive and consistent definition among practitioners and academia' [3]. Basically, a city is an urban environment with a high concentration of population of a country and whose space is arranged to manage its different activities (housing, culture, commerce, education, transportation, traffic, politics, industry, etc. ...). It has its sources in the Neolithic when men stopped moving and being hunter-gatherers (for agriculture, livestock and other activities ...) to settle in a place and to form a community. Since 2009, most of the world's population [10], more precisely $54 \%$ of the world's population in 2014 which should reach $66 \%$ by 2050 [7], live in cities. Each of them has its

*Pape Abdoulaye BARRO. pape.barro@imsp-uac.org different peculiarities, either in developed as well as in emerging or developing countries, that are formerly called underdeveloped countries, where the need to improve the quality of urban life is most pressing.

In terms of the evolution of a city, the path from a "sustainable city" to a "virtual city", must necessarily go through a "smart city", before it can become a "ubiquitous city". A "sustainable city" to which is grafted new computing and communication technologies, and the Internet of Things as well as related technologies (Big data, Cloud computing, cyberphysical systems, networks of communications and sensors, artificial intelligence and embedded systems) can then be considered as a "smart city" when it fulfills a certain number of criteria. The International Telecommunication Union (ITU) in collaboration with the Union Nations Economic Commission for Europe (UNECE) has led the development of an internationally agreed definition of Smart Sustainable Cities (SSC). It says that "A smart sustainable city is an innovative city that uses ICTs and other means to improve quality of life, efficiency of urban operation and services, 
and competitiveness while ensuring that it meets the needs of present and future generations with respect to economic, social, environmental, as well as cultural aspects. » [38]. Initiatives such as that of ITU [37] and that of 'europeansmartcities' [4] are real sources of inspiration. The comparative analysis conducted in [14] emphasized that Songdo / Incheon is the most "equipped" smart city. Singapore, Melbourne, Bodo, Delft and Toronto are not far behind the leader.

The simple fact of considering countries by level of development and cities by level of evolution raises questions on all that has been proposed so far, and in general, leads to a good redefinition of paradigms around smart cities. A layered framework appears to suit better for contextualizing the evolution of communities to future cities. Our main focus will be on "smart city" paradigm for developing countries. In fact, in this context, there is a question about how to clearly adapt the "smart city" concept to see peculiar conditions and the needs of the population, in terms of urbanization and so on. It is expected that the smart city have a positive impact in areas of urban traffic and transport, management of infrastructures, management of garbage, information and communication techniques, population's well-being, simplification of inhabitants 'lives, environment, administrative and governmental approaches, reduction of public expenditure, safety improvement, energy consumption reduction of, quality of education, rental and living costs, productivity (agricultural, industrial, ...), business opportunity, among others .... In this paper, we will discuss the definition of ideological and technological frameworks in order to situate and limit the positioning of a smart city and its components in an evolution towards future cities. We will then adapt it to the developing countries context. A set of research questions is also defined for the future. This also leads to the classification of different works based on the identified components of a smart city, and the definition of indicators to measure the degree of intelligence of each component. In this paper, we will discuss the definition of ideological and technological frameworks in order to situate and limit the positioning of a smart city and its components in an evolution towards future cities. We will then adapt it to the developing countries context. A set of research questions is also defined for the future. This also leads to the classification of different works based on the identified components of a smart city, and the definition of indicators to measure the degree of intelligence of each component. All these concepts are the legwork for an application in air pollution detection, especially in the city of Cotonou, Benin. We will also evaluate the sub-components of the different indicators. This should serve as a reference for current and future cities and a perfect starting point for researchers wishing to go in this direction. Of course, it can be better adapted to cities that start from scratch, as it is the case in many African countries, e.g., Yamoussoukro in Ivory Coast [39] and Diaminadio in Senegal [40], and whose objective is to position themselves in a given evolution standard.

This document will be divided into 7 (seven) sections. Section 2 presents the study background, section 3 presents the methodology, while Section 4 presents and analyzes the previous work review's results as well as setting our vision vis-à-vis the evolution of communities towards future cities. In section 4 , we propose a layered framework that describes suggested progression steps towards future cities. The different technologies, standards and protocols governing the smart cities paradigm are reviewed in Section 6. A general conclusion and a presentation of our next steps will end this document.

\section{Study background}

Cities in developing countries are overflowing with economic, social and environmental imbalances. Many of them are dealing with challenges such as pollution and environmental degradation [31], saturation of transport, clean water and energy availability, public lighting, sewage systems (wastewater treatment), informal or precarious housing (high cost of real estate), population growth (attraction of rural migrants, attraction of the middle and upper classes, etc.) and urban sprawl [32], waste and risks, inequalities of development and social constraints [29], difficulty of access to medical care, illiterate and untrained populations, tough living conditions, neglect of rural agriculture, lack of business opportunities, juvenile delinquency [33], among others. As an illustration, a study [29] reports that in 2009, 97\% of illiterates in the world live in southern countries, $15 \%$ of them in sub-Saharan Africa and the majority of women is living in urban areas. One of the challenges is how to educate and support the most vulnerable. Developed countries don't share these concerns at the same level.

Africa has been urbanizing and organizing itself for a few decades at an exceptionally fast pace [30]. It is more than necessary now, to plan for the development of its cities in sustainability and to make use of intelligent components while adopting what is being done in developed countries and by adding Africa personal peculiarities. It wouldn't be advisable, as for African countries, to jump onboard and to want, at all costs, making the components intelligent. Instead, it is about positioning oneself first, in a given set-theoretic, ideological and technological evolution framework that will be launched, once the key concepts have been well defined. At each step, a certain number of achievable goals will be defined in order not to embark too 
early in non-urgent, immature and very high levels of intelligence.

\section{Methodology}

The proposed methodology is as follows. We first identify all the relevant keywords for the research and constitute what has been called "research string". We have distinguished three namely: (i) sustainability, (ii) "smart cities" OR "smart cities" and (iii) "Internet of things" OR "Web of things" OR "Internet of objects". Our search string was then constructed as follows: (((sustainability) AND ("smart cities" OR "smart cities")) AND ("Internet of things" OR "Web of things" OR "Internet of objects")). This allowed us to go to the appropriate database for data retrieval. This Section is mainly inspired by the 'Research methodology' coined in Samuel Fosso Wamba et al. [34] on 'How Big Data can make a big impact'. With the string constituted, an exhaustive search has been carried out, from 2013 to 2018, in the following databases: "Google Scholar », " IEEE Xplore » and "science direct ». The research began on February 05, 2018 with the supervisors and ended on March 15, 2018. At first, we had 114 articles that we downloaded. We then noted the necessary information such as references, summaries and more. We also made use of EndNote, a reference management software, for data exploitation: Analysis and classification. With this tool, we have finally been able, after filtering the 114 results obtained, to extract only 21 more relevant documents that we use for this survey.

\section{Outcomes}

With the selected 21 papers, it has been a question of examining their approaches in order to highlight what has already been proposed in the literature, but also to be able to position our contribution in this field. The objective is to review the proposals, and also to provide a good framework for researchers wishing to go in this direction. The results are described in two tables. Figure 1 includes the qualitative analysis, the proposals for a frame of reference and/or the comparative studies on the concept of the smart city. Figure 2 describes some applications and achievements encountered in the literature.

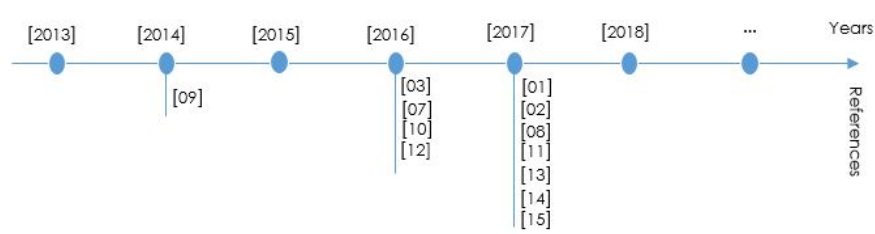

Figure 1. Qualitative Analyzes, Proposed Frameworks and/or Comparative Studies on the Smart City Concept

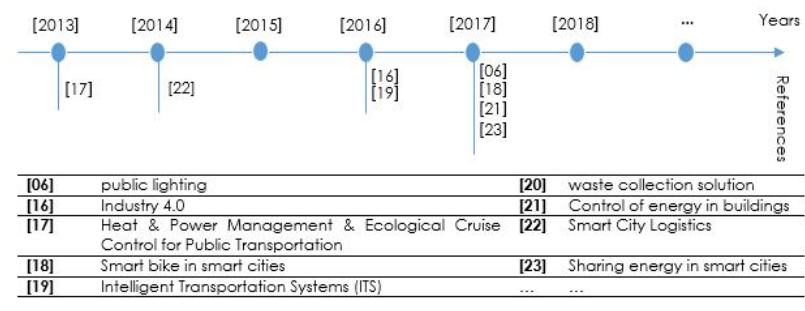

Figure 2. Some achievements encountered in the literature

In the literature, we find vague definitions of the "smart city" paradigm with no specification on the level or degree of intelligence. It is no doubt remarkable that some cities may be smarter than others, depending on their level of development. It would then be wise, after having stated in [12] that "modern cities are becoming more and more intelligent because of the rapid evolution of technology", to foresee stages of evolution of cities in concordance with the evolution of the moment, with the concept of "smart city" as a futuristic approach. In some of these approaches, the notion of Ubiquitous cities (U-cities) [13] is added to Smart cities (SM-Cities), without any proposed ideological framework. This paper will propose some ideas.

Moreover, to achieve the feasibility of the paradigm, various technological approaches have been proposed. There is a well-supplied proposal in [2] on the Internet of Things, except those physical aspects such as embedded systems solutions, sensors, and others that were not clarified. In [8], we can see the key application areas of the Internet of Things, currently, in the future, and it offers some challenges for Smart Cities. Inspired by these few technical contributions, the expansion to take into account at least, Big Data [3], Cloud computing and artificial intelligence will be a strong asset in the implementation of "future cities".

\section{Ideological framework}

According to the ideological approach adopted in this document, the smart city paradigm is part of the steps towards future cities. In reality, a city is evolving. It is first considered as a community (CM), then with the growth of its population, it becomes a city (CITY) with a pressing need to evolve to a sustainable city (S-CITY). This is the case in most developing countries. Once durable, it will then be the quest for becoming intelligent (SM-CITY), then ubiquitous (U-CITY), then digital (D-CITY) and then virtual (VCITY) while evolving to future cities in agreement with news technologies. This evolution can be seen as a setinclusion, one encompassing the other, and so on. It can then be seen as follows:

A "sustainable city" or S-CITY, is a city that builds their development around the social, economic and 


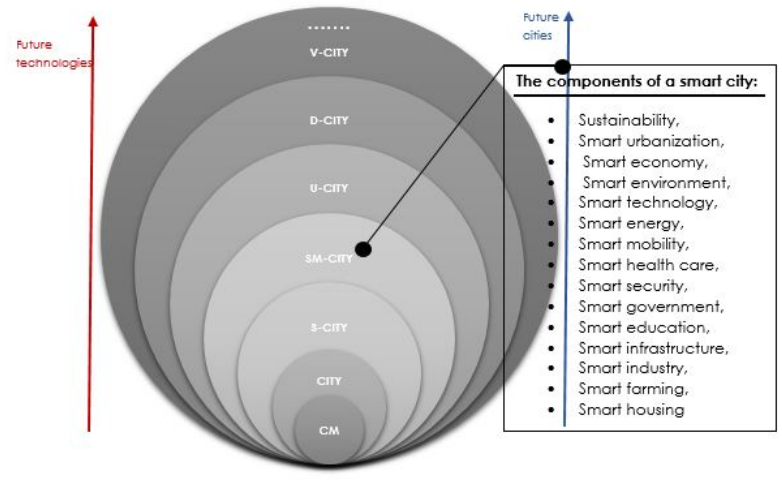

Figure 3. Ideological proposal towards future cities in line with new technologies

ecological aspects to ensure as much as possible, the balance, viability and livability of the area, in all complicity with the actors of the ecosystem (citizens, organizations, businesses and city managers). According to the World Bank [24], sustainable development is based on three pillars: economic growth, environmental management and social inclusion. This is true for all dimensions of development: rapid urbanization, agriculture with climate change, infrastructure, energy production and use, water and low carbon transport.

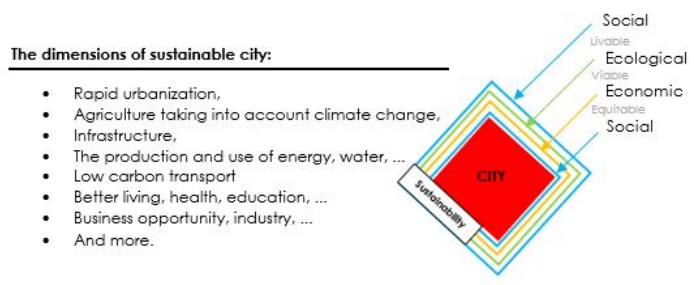

Figure 4. Model of a sustainable city

"Smart cities" or SM-CITY have been approached in a variety of ways. In [1], the term is defined as' a general concept that contains a number of subthemes such as smart urbanism, smart economy, sustainable and smart environment, smart technology, smart energy, smart mobility, smart health, and so on. In [2], a "smart city is a complex ecosystem characterized by the intensive use of ICT, which is more attractive and more sustainable and has a unique place for innovation and entrepreneurship". [3] Tells us that 'In a simplistic explanation, a smart city is a place where it is more flexible, efficient, and sustainable with the use of information, digital and telecommunication technologies, to improve its operations for the benefit of its inhabitants. Smart cities are greener, safer, faster and friendlier. The different components of a smart city include smart infrastructure, smart transportation, smart energy, smart healthcare, and smart technology.
These components are what makes the cities smart and efficient. Then in [12]: 'Smart cities are an endeavor to make cities more efficient, sustainable and livable. In other words, a smart city is a city that can monitor and integrate all critical infrastructure like roads, tunnels, airways, waterways, railways, communication power supply, etc., control maintenance activities and can help in optimizing the resources while keeping an eye on the security issues as well. A smart city is a smart version of a sustainable city. It has the particularity to bring intelligence in the dimensions of a sustainable city thanks to the new technologies of information and communication.

Ubiquitous is more than just a consideration of a "smart city". It allows anytime and anywhere to have real-time data and to be able to observe a continuous evolution of a device in a "sustainable and smart city". In [13], it is quoted that 'In a u-city, digital devices such as computers will become part of an environment in which any user can continually interact with hundreds of interconnected digital devices at anytime and anywhere and therefore be able to make decision based on the information available, just like a human. Cargo and other devices (e.g., smartphones, and computers), and various personal devices (e.g., smart phones, and computers), and all these entities are connected via digital networks based services'. This allows us to define the paradigm "Ubiquitous city or U-CITY ", a city full of intelligent robots, smart cars without drivers, high urbanization, hearts and other connected organs, etc....

"Digital city or D-CITY" is a city where the harmonious feeling is present, where the information is shared intelligently, where the collaboration has become much more fluid and intelligent, etc.

Virtualization refers to the ability of a city to make virtual paths for flying machines, virtual bodies for high medicine, holograms for high communication, etc.... It allows introducing the paradigm "Virtual city or $\mathrm{V}$ CITY ", a city largely above the "Ubiquitous cities".

Table 1 presents for each given step, the few components that can be expected at least in order to determine the evolution steps.

\section{Technological framework}

According to [3], Information and communication technology (ICT) is enabling keys for transforming traditional cities to smart cities. The two closely related emerging technology frameworks that are Internet of Things (IoT) and Big Data (BD) make smart cities efficient and responsive. [7] states that 'Smart Cities are: sensitive (sensors sense the environment), connectable (networked devices bring the sensed information to the Web), accessible (information on our environment is published and accessible by users on the Web), ubiquitous (users can access information at any time 
Table 1. Summary of the components of the different steps of the ideological model

\begin{tabular}{l|l}
\hline Steps & Components \\
\hline Community or CM & Agriculture, livestock and other activities ... \\
\hline $\begin{array}{l}\text { Traditional city or } \\
\text { city or CITY }\end{array}$ & $\begin{array}{l}\text { Community, population growth, housing, } \\
\text { culture, commerce, education, transportation, } \\
\text { traffic, politics, industry, etc.... }\end{array}$ \\
\hline & $\begin{array}{l}\text { Rapid urbanization, agriculture taking into } \\
\text { account climate change, infrastructure, } \\
\text { the production and use of energy, water, ..., } \\
\text { low carbon transport, better living, health, } \\
\text { education, ..., business opportunity, industry, ..., } \\
\text { etc.... }\end{array}$ \\
\hline S-CITY & $\begin{array}{l}\text { Sustainable Cities, Smart Urbanization, } \\
\text { Smart Economy, Sustainable and Smart } \\
\text { Environment, Smart Technology, Smart } \\
\text { Energy, Smart Mobility, Smart Health Care, } \\
\text { Smart City or } \\
\text { SM-CITY } \\
\text { infrastructure, Smart industry, Smart farming, } \\
\text { etc. ... }\end{array}$ \\
\hline Sbiquitous city or & $\begin{array}{l}\text { Smart city, Smart robots, smart cars, } \\
\text { Smart lighting, Smart parking, location } \\
\text { services, high urbanization, hearts and } \\
\text { other connected organs, etc. ... }\end{array}$ \\
\hline U-CITY & $\begin{array}{l}\text { Intelligent collaboration, harmonious feeling, } \\
\text { intelligent sharing of information, etc. ... }\end{array}$ \\
\hline Digital city or & $\begin{array}{l}\text { The Ubiquitous city, virtual paths for flying } \\
\text { machines, virtual bodies for high medicine, } \\
\text { holograms for high communication, etc. ... }\end{array}$ \\
\hline D-CITY &
\end{tabular}

and any place, while moving), sociable (users acquiring information can publish it on their social network), sharable (sharing is not limited to used when they are in free status), and visible / augmented (the physical environment is retrofitted and not only by individuals through mobile devices, but also in physical places such as street signs). Then in [10]: "Smart City is a city in which its social, business, and technical aspects are supported by Information and Communication Technologies to improve the experience of the citizen within the city. To achieve this, the city provides an integrated, affordable, and sustainable way. It can then be considered as the crossroads between sustainable development and information and communication technologies (embedded systems, IoT, Big Data, Cloud computing, artificial intelligence ...) within a city in full demographic growth.

Embedded systems, often real-time, are autonomous electronic and computer systems. They consist of a hardware part and a software part and their architectures are built around a microcontroller. They have specific peripherals and sensors for their applications and are easily grafted into the objects we use on a daily basis. As an application, we can mention the Arduino microcontroller, the Raspberry microcomputer, Beaglebone, Galileo, the Particle.IO range, the MicroPython range, etc....

Internet of Things is undeniably one of the most popular technological phenomena of our day. According to the ITU (International Telecommunications Union) [5], "Internet of Things (IoT) is a global infrastructure for the information society, which provides advanced services by interconnecting objects (physical or virtual) through existing or evolving interoperable information and communication technologies ". There are many other considerations in the literature, this is the case in [6] which says that 'In IoT, everyday life objects are "smart", i.e., they are uniquely identifiable and are equipped with computing, storage and sensing capabilities and can communicate one with each other and with the users to enable pervasive and ubiquitous computing'. He also considers [8] that 'IoT can be typically defined as a real object, largely dispersed, with low storage capabilities and processing capacities, while aiming at enhancing reliability, performance and security of the smart cities as well as their infrastructure'. According to Gartner, Inc. [25], 8.4 billion connections will be used worldwide in 2017, up 31\% from 2016 and will reach 20.4 billion by 2020 . Total expenses for terminals and services will reach nearly \$ 2 trillion in 2017. China, North America and Western Europe account for $67 \%$ in terms of using the Internet of Things (IoT) in 2017. In Internet of Things, one meets a set of communication protocols [8] (see Figure) and application protocols [36] (CoAP (Constrained Application Protocol), MQTT (Message Queuing Telemetry Transport), XMPP (Extensible Messaging and Presence Protocol), AMQP (Advanced Message Queuing Protocol), and so on.

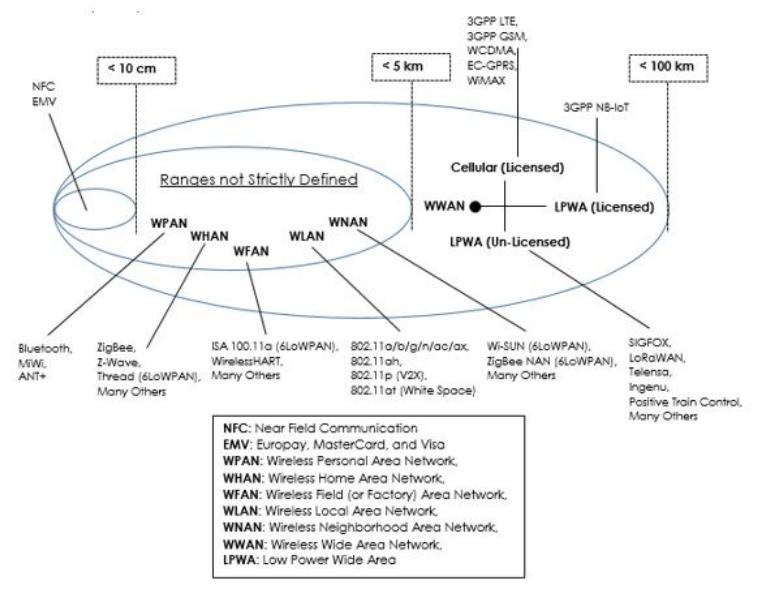

Figure 5. Access Technologies and Distances (Inspire on the Cisco book: loT Fundamentals)

A large amount of data will be put into play to the point that its management and processing exceed those of conventional computer tools for database management or information in general. " 
This phenomenon is mainly driven by the widespread diffusion and adoption of mobile devices, social media platforms including YouTube, Facebook and Twitter, and 'Internet of Things' related concepts (e.g., RFID technology) » [34]. The concept of Big Data, its current and future treatment approaches and challenges [3], will then help to address most of these fears. According to Oracle [26], Big Data describes a holistic information management strategy that includes and integrates many new types of data and data management as well as traditional data. It is defined, at least, by the four notions or characteristics namely the Volume (the amount of data), the Speed (the speed at which the data is received and possibly processed), the Variety (new types of unstructured data) and Value (the intrinsic value of the data must be discovered).

Increasing the data collected and the need to always access information will become an essential factor in future cities. Cloud computing can then serve as a base for storing and analyzing data. It can, for this purpose, host Big Data solutions and thus allow better data processing. "[27] Clouds are a wide range of easily usable and accessible virtualized resources (such as hardware, development platforms and/or services). These resources can be dynamically reconfigured to accommodate a variable load, which also allows for optimal resource utilization. Generally operated by a " pay-per-use " model in which guarantees are offered by the infrastructure provider ". In other words, " [28] cloud computing is a model for accessing a network of configurable resources (for example, networks, servers, storage, applications and services) allowing dial-up access to the network and at the same time, requires a shared pool that can be quickly provisioned and distributed with minimal management effort or interactions between service providers ". In the cloud, it often refers to Software as a Service (SaaS), Platform as a Service (PaaS), and Infrastructure as a Service (IaaS).

For components to be more sensitive to changes in their environments, it is necessary to instill in them knowledge and reasoning. "Artificial intelligence (AI) entities and systems have the ability to perform operations analogous to learning and decision making by imitating biological processes, with special emphasis on human cognitive processes » [35]. " Artificial intelligence $(\mathrm{AI})$ is an extensive scientific discipline which enables computer systems to solve problems by emulating complex biological processes such as learning, reasoning and self-correction » [35]. Artificial intelligence (AI) can be added wherever the need for learning and reasoning is felt, for example, in smart vehicles (driverless vehicles), voice recognition or smart home appliances, or at the level of virtual assistantship and prediction. It can play a big role in improving
Table 2. Summary of the Technology Framework for Smart and Future Cities

\begin{tabular}{l|l}
\hline Concept or technology & components \\
\hline \multirow{3}{*}{ Embedded Systems (ES) } & $\begin{array}{l}\text { Arduino, Raspberry, Beaglebone, Galileo, } \\
\text { the Particle.IO range, the MicroPython } \\
\text { range, etc.... }\end{array}$ \\
\hline Internet of Things (IoT) & $\begin{array}{l}\text { Networks, protocols and communications } \\
\text { standards, service providers, embedded } \\
\text { systems, etc. }\end{array}$ \\
\hline Big Data & $\begin{array}{l}\text { Large data management: Volume, Speed } \\
\text { of reception and processing, Variety in } \\
\text { terms of data type and discovery of } \\
\text { intrinsic value of data ... }\end{array}$ \\
\hline Cloud Computing & $\begin{array}{l}\text { On-demand self-service, fast resizing } \\
\text { (elasticity) and scale growth management, } \\
\text { high availability and pay-per-use. }\end{array}$ \\
\hline \multirow{3}{*}{ Artificial Intelligence } & $\begin{array}{l}\text { Intelligent vehicles, virtual assistantships, } \\
\text { prediction, improving productivity, } \\
\text { improving safety, improving human health, } \\
\text { improving the way of entertaining or } \\
\text { improving the way of communicate, ... }\end{array}$ \\
\hline
\end{tabular}

productivity, safety, human health, and the way we entertain or communicate...

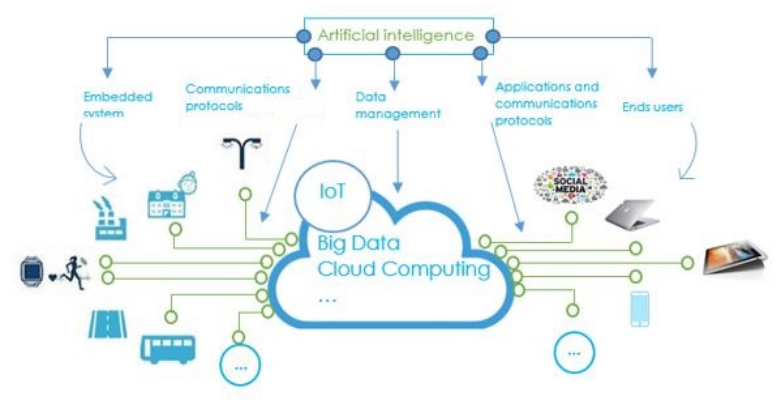

Figure 6. Technical framework for future cities

The quintet "Embedded Systems, IoT, Big Data, Cloud Computing, Artificial Intelligence" as well as their future challenges will constitute an ecosystem that will allow the feasibility of future cities. Nowadays, IoT and Big Data are in great demand. They rely on the Cloud, which represents the foundations of this ecosystem. Below is the summary table of the technology framework for smart and future cities.

It is essential, in the technical framework of future cities implementation, to take into account, among others, certain requirements such as lowcost deployment which is key for sustainability, security, privacy, low and green energy consumption, interoperability which is based on standards, scalability to cope with the growth, reliability, speed in routing and data processing, high availability... 


\section{Conclusion and next step}

Overall, a smart city is a futuristic approach as it evolves with the technology. It can start as a simple community, and reach the level of a virtual city while evolving towards a future city. In most developing countries, with the fast growth of the population, the cities feel a pressing need to evolve to sustainable cities. The case of Africa, which is urbanizing and organizing itself at a slower pace, really needs some precautions and a step by step evolution framework, with the clear definition of the requested components at each step. This is in order not to wrongly launch earlier, early, non-urgent, immature and very high-level puzzle of rather intelligent achievements. In the age of embedded systems, the Internet of Things, artificial intelligence, big data and cloud computing, it is more than interesting to build smart cities based on a given progression dynamic.

This paper presents a thorough review of previous works as well as proposed an ideological and technical framework with some emphasis on developing country's needs. Of course, a lot of achievements or models exist, especially in developed countries, however, it is not a quest for copying and pasting, but to impregnate as much as possible on the existent in order to build the required components according to the contexts and the realities of each locality. As for researchers, the idea is not to replicate, but to evolve and adapt science and technology.

As a next step, we will conduct a qualitative analysis (classification) of the work on smart city (SMCITY) components, and propose a way to evaluate its components and to appreciate its level of intelligence.

Acknowledgement. We thank the people who, near or far, participated in this work. We also thank the reviewers and future researchers for their interest in this article.

\section{References}

[1] Trindade E. P., Hinnig M. P., da Costa E. M., Marques J. S., Bastos R. C. and Yigitcanlar T. (2017) Sustainable development of smart cities: a systematic review of the literature (Journal of Open Innovation), .

[2] Menmood Y., Ahmad F., Yaqoob I., Adnane A., Imran M. and GuIzani S. (2017) Internet-of-Things-Based Smart Cities: Recent Advances and Challenges (IEEE Communications Magazine), Pages: 16 - 24.

[3] Mohanty S. P., Choppali U. and Kougianos E. (2016) Everything you wanted to know about smart cities: The Internet of things is the backbone (IEEE Consumer Electronics Magazine), Pages: 60 - 70.

[4] EUROPEANSMARTCITIES The smart city model (http://www.smart-cities.eu/?cid=2\&ver=4)

[5] ITU-T Présentation générale de l'Internet des objets (https://www.itu.int/rec/T-REC-Y.2060-201206-I/fr)
[6] Cacciatore G., Fiandrino C., Kliazovich D., Granelli F. and Bouvry P. (2017) Cost analysis of smart lighting solutions for smart cities (IEEE International Conference on Communications (ICC)), Pages: 1 - 6.

[7] Cassandras C. G. (2016) Smart Cities as Cyber-Physical Social Systems (Engineering), Pages 156-158.

[8] Talari S., Shafie-khah M., Siano P., Loia V., Tommasetti A. and Catalão J. P. S. (2017) A Review of Smart Cities Based on the Internet of Things Concept (Energies).

[9] Zanella A., Bui N., Castellani A., Vangelista L. and Zorzi M. (2014) Internet of Things for Smart Cities (IEEE Internet of Things Journal), Pages: 22 - 32 .

[10] Santana E. F. Z., Chaves A. P., Gerosa M. A., Kon F. and Mirojicic D. S. (2016) Software Platforms for Smart Cities: Concepts, Requirements, Challenges, and a Unified Reference Architecture (ACM Computing Surveys).

[11] Perera C., Qin Y., Estrella J. C., Reiff-Marganiec S. and Vasilakos A. V. (2017) Fog Computing for Sustainable Smart Cities: A Survey (ACM Computing Surveys), .

[12] Joshi S., Saxena S., Godbole T. and Shreya. (2016) Developing Smart Cities: An Integrated Framework (Procedia Computer Science), Pages 902-909.

[13] Rad T. G., Sadeghi-Niaraki A., Abbasi A. and Choi S. M. (2018) A methodological framework for assessment of ubiquitous cities using ANP and DEMATEL methods (Sustainable Cities and Society), Pages 608-618.

[14] Vidiasova L., Kachurina P. and Cronemberger F. (2017) Smart Cities Prospects from the Results of the World Practice Expert Benchmarking (Procedia Computer Science), Pages 269-277.

[15] Lacinák M. and Ristvej J. (2017) Smart City, Safety and Security (Procedia Engineering), Pages 522-527.

[16] Lom M., Pribyl O. and Svitek M. (2016) Industry 4.0 as a part of smart cities (IEEE Conferences), Pages: 1 - 6 .

[17] Kyriazis D., Varvarigou T., White D., Rossi A. and CoOper J. (2013) Sustainable smart city IoT applications: Heat and electricity management and Eco-conscious cruise control for public transportation (IEEE 14th International Symposium on "A World of Wireless, Mobile and Multimedia Networks" (WoWMoM)), Pages: 1 - 5.

[18] Makarova I., Shubenkova K., Mavrin V., Boyko A. and Katunin A. (2017) Development of sustainable transport in smart cities (IEEE 3rd International Forum on Research and Technologies for Society and Industry (RTSI)), Pages: $1-6$.

[19] Di Martino S. and Rossi S. (2016) An Architecture for a Mobility Recommender System in Smart Cities (Procedia Computer Science), Pages 425-430.

[20] Gutierrez J. M., Jensen M., Henius M. and Riaz T. (2015) Smart Waste Collection System Based on Location Intelligence (Procedia Computer Science), Pages 120-127.

[21] Khajenasiri I., Estebsari A., Verhelst M. and Gielen G. (2017) A Review on Internet of Things Solutions for Intelligent Energy Control in Buildings for Smart City Applications (Energy Procedia), Pages 770-779.

[22] NowickA K. (2014) Smart City Logistics on Cloud Computing Model (Procedia - Social and Behavioral Sciences), Pages 266-281.

[23] Zuccalà M. and Verga E. S. (2017) Enabling Energy Smart Cities through Urban Sharing Ecosystems (Energy Procedia), Pages 826-835. 
[24] BANQUEMONDIALE Développement durable. (http://www.banquemondiale.org/fr/topic/sustainable development/overview)

[25] GARTNER (https://www.gartner.com/newsroom/id/3598917)

[26] Oracle Big Data. (https://www.oracle.com/fr/bigdata/index.html)

[27] Vaquero L. M. Rodero-Merino L. Caceres J. and LINDNER M. (2009) A break in the clouds: towards a cloud definition (ACM Digital Library), Pages 50-55.

[28] Zhang Q. Cheng L. and Boutaba R. (2010) Cloud computing: state-of-the-art and research challenges (Journal of Internet Services and Applications), pp 7-18.

[29] Etudier Le developpement durable, une reponse aux problemes des villes $d u$ sud. (http://www.etudier.com/dissertations/LeDeveloppement-Durable-Une-ReponseAux/513223.html)

[30] Etudier Villes d'afrique. (http://www.etudier.com/dissertations/Villesd'Afrique/181875.html)

[31] Etudier Développement durable et les villes du sud. (http://www.etudier.com/dissertations/DéveveloppementDurable-Et-Les-Villes-Du/477964.html)

[32] Etudier Villes et développements durables. (http://www.etudier.com/dissertations/Villes-EtDéveloppements-Durables/382460.html)

[33] Etudier L'afrique et le developpement. (http://www.etudier.com/dissertations/l'Afrique-EtLe-Developpement/62382.html)
[34] Wamba S. F., Akter S., Edwards A., Chopin G. and GNanzou D. (2015) How 'big data' can make big impact: Findings from a systematic review and a longitudinal case study (International Journal of Production Economics ), Pages 234-246.

[35] Mata J., de Miguel. M., Durán R. J., Merayo N., Singh S. K., Jukan A. and Chamania M. (2018) Artificial intelligence (AI) methods in optical networks: A comprehensive survey (Optical Switching and Networking), Pages 4357.

[36] BENFATTOUM A. (2015) QUELS PROTOCOLES APPLICATIFS POUR L'INTERNET DES OBJETS ? (https://www.frugalprototype.com/quels-protocolesapplicatifs-pour-linternet-des-objets/).

[37] International Telecommunication Union [ITU] Smart Sustainable Cities. (https://www.itu.int/en/ITU$\mathrm{T} / \mathrm{ssc} /$ Pages/default.aspx)

[38] International Telecommunication Union [ITU] Striving for SUSTAINABLE DEVELOPMENT. (http://wftp3.itu.int/pub/epub_shared/TSB/2016ITUT-SSC-Brochure/en/index.html\#p=1)

[39] [Côte d'Ivoire] Yamoussoukro ville numérique et ville du futur. (http://www.lactuwebdedith.com/2016/01/cotedivoire-yamoussoukro-ville.html)

[40] Diamniadio, une Smart City Sénégalaise. (https://medium.com/@pulseafrique/diamniadio-smartcity-senegalaise-23b248c9b52d) 